\title{
Strategic Human Resource Planning: Responding to Changes Dynamic Business Environment and Effective to Achieve Competitive Advantage
}

\author{
Siti Normi, SE, M. Si \\ University lecturer Methodist Indonesia
}

Received: February 26, 2017 Accepted: March 26, 2017 Published: March 28, 2017

doi: 10.5296/jsss.v4i2.10995 URL: http://doi.org/10.5296/jsss.v4i2.10995

\begin{abstract}
This article discusses human resource planning issues as strategy to response dynamic and competitive business environment changes to gain sustainable competitive advantage. Also this article discusses how the stages and human resource planning process in short term, intermediate term and long term, and discusses about how long the linkage between humen resource and strategic business planning are administrative linkage, one-way linkage, two-way linkage, and integrative linkage. The last section in this article discusses the importance gaining competitive advantage sources and human resource concentration related with business issues as the action to integrate human resource fuction in the strategic business.
\end{abstract}

Keywords: Strategic human resource planning, Dynamic environment change, Strategic business, Human resource fuction, Competitive advantage

\section{Preliminary}

Dynamically changing business environment, organizations require to adapt to these developments. This phenomenon is considered by the level of radical changes in business environment and turbulent, with the increasing level of uncertainty, increased competitive pressures, the acceleration of technological change, the complexity of the organization, changes in the demographic structure (Schuler \& Walker, 1990). These changes will lead to the recognition of the increasing importance of human resources in responding to changes which occurred, very decisive advantage komptitif organization (Pfeffer, 1995).

Changes in the business environment as indicated by the development of communication technology and information technology is a major challenge facing HR today. Thus the human resources that have a low potential are not able to compete due to technological developments, organizational mengurangitenaga rough work (blue collar employee) and 
replace manpower to accommodate changes and developments in technology. Human resources involved in the process of managerial organization is human resources that have the knowledge base (knowledge based employee), skills and expertise (multiskilling employee). Competitive advantage (sustainable competitive advantage) is not entirely determined by technology or other resources, but rather lies in the ability of the organization in human resource management (Pfeffer, 1995). The competitive advantage of the organization can be achieved if the organization has a strategic human resource management and competitive (Pfeffer, 1995). HR issues regarding the supply of skilled human resources, which has the adaptability and competitive continues to be a central issue. HR has a strategic contribution to business success. Because HR issues are business issues that affect the substance of the business such as profitability, existence, competitiveness, adaptability, and flexibility.

Anticipating this phenomenon, the needed human resource planning (human resources planning) to obtain the number, the time and the right place, which effect on profits of individuals and organizations in the long term. Through HR planning, it can be determined how people move from position this time to the desired position. It takes strategy and business integration in HR planning (Vickerstaf, 1989). The need to integrate aspects of strategic HR planning into business development should guarantee HR planning as a line responsibility (Rothwell, 1995). With the organization's HR planning is expected to be able to manage the available human resources towards improving the competence and quality of human resources, in order to obtain a competitive advantage in order to win the competition in an increasingly competitive business environment (Dessler, 2000).

This article will discuss how the stages and HR planning processes in three terms, namely short-term human resource planning (short term), medium term (intermediate term), and long-term (long term). Furthermore, this article discusses how the relationship between HR planning with a business plan that includes administrative linkage, linkage one way, two way linkage and integrative linkage. At the end of the discussion to discuss the urgency of competitive advantage (competitive advantage) and HR planning linked with business issues as the integration of HR functions in the organization's business strategy, discuss HR planning strategic to respond to the changing dynamic business environment and increasingly competitive to gain a competitive advantage, thereby competition in the business environment can be won.

\section{Human Resources Strategic Planning}

HR planning is defined as the anticipation of future business and environmental demands on the organization and bring personal requests ordered by the condition (Cascio, 1986). While Jackson and Schuller (1990) defines human resource planning as a management process to determine how the organization should move from position to position HR HR is now desired. This implies, HR planning can be an important input to the strategic planning. However, the link between strategic human resource planning by management is often overlooked (Baird \& Meshoulam, 1988; De Santo, 1983; Olian \& Rynes, 1984; Rowland \& Summers, 1981). Through this process, organizations expected to have the human resources in the quantity, quality, place, right time, and generate long-term benefits for both individuals and organizations.

Many researchers focused on forecasting the supply and demand of human resources. 
Problems statistical techniques available to make predictions, but the political problems involved when forecasting is often overlooked. For example, do a big concern when designing a statistical model in human resource planning, while rarely thought to acquire managerial acceptance of the model output (Zedeck \& Mosier, 1990). Because of the gap that often arises between the availability of techniques to use due to the fact important organizations do not cooperate with the model.

However managerial replacement planning related to strategic business planning. Identifying potential managers and provides a series of his career has been the practice of many organizations, but managers have to implement the strategy. Lack of effort devoted when adapting strategies for managers and almost no effort when selecting a manager to plan strategy.

\section{Responses to Environmental Change Strategic Business; Reason Importance of Human Resources Strategic Planning}

Environmental factors such as uncertainty, technological innovation, and demographic changes affecting HR strategy. Many environmental characteristics have been studied to determine how the environment is limiting formulation of the HR or strategies (Fombrun, 1982). Fombrun (1982) argues, changing technology environment has a great influence on HR. Changes in the economic environment directly affects the alternative compensation and human resources training. Changes in the social environment associated with changes in organizational development and the promotion of formal HR assessment system, where the political environment is hypothesized to have a strong pangaruh for success and the organizational commitment and career counseling.

At the beginning of this article has discussed the urgency of HR planning. Pressure dynamic business environment and competitive is the reason for the need for HR planning. Jackson \& Schuller, (1990) suggested some environmental pressure, among others; globalization, the emergence of new technology, economic conditions, and changes in the characteristics of human resources. Globalization, as the tendency of organizations to expand sales or manufacturing them into new markets outside the country. The advent of globalization has increasingly blurred boundaries between countries, and likely to lead to the formation of "boundaryless organization" which memobilitas information, technology, resources, investment and industrial operations is increasing, these conditions increase in global competition (Dessler, 2000). The emergence of new technologies, demand HR is able to control the technology changes. Economic conditions; also requires that companies improve productivity toward better to be highly competitive amid an increasingly competitive business environment. Finally, changes in the business environment is also changing the HR-specific characteristics, it is due to the demographic problem for example, the declining number of young labor force and non-productive, productive age on the other hand, women workers, and racial diversity in the workforce is increasing (Rothwell, 1995).

\section{Strategic HR Planning Stages}

Planning in defining the overall strategy to achieve goals, develop comprehensive plans to coordinate and mengintegrsikan activity. This plan focuses on what to do and how their implementation. As such they should be made a step in the planning process. HR planning 
steps include (Jackson \& Schuller, 1990): (a) collect and analyze data to estimate the expected human resources, planning of future business, and predict demand for resources; (B) set the goal of human resources; (C) design and implement programs that will help the organization reach the goal of human resources, and; (D) monitor and evaluate these programs.

All activities are covered in the fourth phase will be divided into three periods, namely planning short term (less than one year), intermediate term planning (two or three years), and long term planning (over three years).

\section{Short-Term Human Resource Planning}

Experts industrial organizational psychology or perform activities related to designing and implementing such programs, withdrawal, system selection, training courses to obtain short-term needs of the organization. Many activities in general involve some element of planning oriented fore expanded. Even projects to which they achieved objectives expected within a short time, eg for several months, has been designed with an understanding of how short-term objectives related to the achievement of long-term goals (Jackson \& Schuler, 1990).

To explain the linkages between HR planning and strategic business planning, it is very important for top management to have a vision of the future where that vision is communicated and acceptable to all the managers of the organization (Jackson \& Schuller, 1990).

\section{Estimating Demand and Short Supply}

With the short-term horizon of human resources supply and demand can be predicted with certainty, including;

(1) The purpose of HR planning saw a mismatch between demand and supply. Requests, including the number and characteristics of people who need a particular job at a particular time and place. Characteristics HR includes the talents, skills or experience the wage rate. Offer includes payments and HR experience available to certain position.

(2) As a way to estimate jobs and growth, with a tendency of projecting the past into the future.

(3) The estimated number and type of jobs that will be eliminated or created in the short term will follow the business planning carried out by the line manager.

(4) Characteristics of existing jobs and the potential for inventoried and run by SDM is influenced by the nature of the organization and the organizational environment.

(5) In the planning of human resources is very important to know the characteristics and business purposes, which is obtained by conducting meetings with line managers. The process of discussion with the parties involved in short-term human resource planning will increase the accuracy in estimating the human resources and facilitate goal setting.

\section{Determination of Short-Term Goals}

With the short-term horizon will set a term that can be easily measured. Short-term HR planning objectives include:

(1) Improving human resources to the organization interested in applying for a job. 


\section{I Macrothink}

(2) Recruiting candidates differ in their human resources expertise.

(3) Improve the criteria of the new payroll.

(4) Increase the length of time for the human resources working in the organization.

(5) On the contrary decrease the length of time that does not want HR working in the organization.

(6) Providing human resource development for the old and new in the expertise needed organization. Many general purpose can be achieved by applying the techniques of art HR management and working with line managers to ensure understanding program goals

\section{Design and Implement Short-Term Programs.}

Expertise psychological techniques are often applied in the design and implementation of short-term programs, such as;

(1) Recruiting, this program uses psychological skills in order to influence the size and quality of candidates SDM.

(2) Selection, used to increase hiring program.

(3) Appraisal, the program is to identify those capabilities are used for the award.

(4) Training, the program is aimed at the development of human resources expertise.

(5) Compensation, the program prepared for payroll, HR interesting new, motivate and retain human resources to be more productive.

\section{Evaluation of Short-Term Programs}

Evaluation of short-term programs are needed to assess the extent to which percapaian short-term goals. Short-term planning goals and evaluation measured SDM program is used to determine the feasibility of short-term purposes of the organization. Short-term HR planning called HR Strategy. The strategy focuses how HR management. In this strategy, there are several complementary activities as factors supporting the creation of the HR Strategy (Schuller \& Walker, 1990), among others:

(1) In response to environmental changes.

(2) Using the orientation of the manufacturing business and HR agenda.

(3) Pay attention to business relations and human resources integral in achieving successful organizational change accommodation.

(4) Line managers should be more involved in this activity.

Evaluation of short-term HR planning is sometimes there are some fundamental changes and is of particular concern for human resources, Changes the fundamental, among others:

(1) Change is rapid and full of uncertainty business environment.

(2) There is a change or increase in cost competitive due to increasing competition and declining profit margins.

(3) Acceleration change rapid technology thus requires new competencies through education and training.

(4) The complexity of the organization in terms of products, locations, technology used, as well as the customers and markets.

(5) The existence of organizational change towards a flat and lean, making it more flexible. 
(6) The change in the demographic aspects, which could cause a shortage of human resources needed.

(7) Therefore, there needs to be an appropriate response to changes in external forces.

(8) The increased competition of multinational, multilateral alliances and cooperation relations.

The above problems should be identified by collecting the necessary data and perform analysis of this problem so that it will facilitate planning strategies SDM.yang made. The approach taken should focus on existing problems, thus the company will be able to;

(1) Knowing their wishes and eliminating gaps or problems existing problems.

(2) Selective and focus on important issues as well as the right to do to overcome them.

(3) Develop commitment and quickly act on urgent matters.

Orientation on HR issues is essentially a business issue, thus organizations must maintain management's view and not just in view of the HR department staff. They should also allocate resources so that the mission and business objectives can be achieved. So that strategic planning is effective should pay attention to things like the issues and strategies should be communicated to all levels of the organization, improve management effectiveness (such as responsibility, capacity, accountability, and recognition) in the implementation of these plans, as well as re-evaluate and modify the process HR and operations staff functions to support the implementation of the strategy. Thus the strategic HR planning can be successful if it is supported by the existence of a condition such as:

(1) The planning strategies that consider the environment and human resources.

(2) The planning strategies using quantitative and qualitative input.

(3) The Company has a specific strategy.

(4) The Company has a group planning maker who has a high commitment to strategic planners.

(5) Taking into account the role of the external environment and the attention of HR planning must consider the related business people.

(6) The need to empower line level managers to be involved in identifying issues of HR as a strategic issue, as well as in strategic business planning.

\section{Medium Term Human Resource Planning}

As it is known that planning is used by organizations to support the delivery of products or services from sources that are uncertain. HR program for the recruitment, selection, training, and motivation of human resources help to reduce uncertainty by ensuring that the number of people with the expertise required characteristics and are available at all levels of the organization. Changes in the business environment that quickly cause the foreseeable future is not easy to anticipate memlalui past trends. The focus moves from short-term planning for the medium-term with regard to the question "what will we need", and in the medium-term planning is something that is more uncertain is related to the question "what will be available". In the medium term HR foresee it takes a lot of attention on technical matters, because in the medium-term period of uncertainty the higher level. In the medium term HR planning begins with forecasting supply and demand which is not much different from the 
short-term human resource planning, and goal setting and program development. Increased uncertainty is aware of the importance of interaction between HR planner with line managers in order to make the supply and demand forecasting lebi critical and accurate.

\section{Estimating the Demand and Supply of the Medium-term}

In predicting the number and quality of human resources required in order to run a successful organization work well over the medium term, organizations need to estimate the organizational outputs such as production, sales volume is desired. The desired output by using a technology that is used, determine the human resources required.

This requires a human resource demand forecasting; (1) suatau accurate model of the factors affecting demand and; (2) ability to predict the state of all the main variables in the models used. Organizations operating in a stable environment can create a model that incorporates the major factors to determine the demand for the next three years. Often several organizations quantify the expected value of the variable in the model, with statistical forecasting techniques such as regression analysis, time series, or stochastic modeling. But for organizations of operating in an unstable environment, forecasting for three years at risk of high uncertainty because both the variable and the value of which is expected to be more difficult to be accurately determined based on historical data.

The complexity of forecasting this statiskal encourage use techniques judgmental. Type judgmental forecasting one of which is the estimated managerial; which estimates kebutuhahn staffing can be done by mid-level managers and line the bottom, after which the results obtained can be forwarded to top management and if necessary revision or repair and then in turn shape the overall demand forecasting. Another type of judgmental forecasting better often known as the Delphi technique sebuatan. In this Delphi technique, decision-making methods deliberately designed to maximize the benefits and minimize the dysfunctional aspects of group decision-making. Estimates of managerial and engineering Delphi keduannya focused on forecasting the amount of human resources required. The downside of this model override attention to quality aspects such as the ability and expertise of human resources in the future, which is really very necessary.

While forecasting HR deals may come from internal or external resources. In general, internal resources more widely available, but in the medium term forecasting deals also needed human resource information coming from external sources. As demand forecasting, on forecasting these deals also may be used technique statistikaldan judgmental. Usually judgmental technique that is often used is to predict deals replacement (replacement planning). Statistical techniques are often used to predict HR deals include Markov analysis, inventory models, simulation (based on Markov analysis), goal programming, and renewal analysis. Statistical methods for forecasting HR deals consist of two phases, which collect inventory on the current bid (including the number of people, skills and abilities) and predict how changes in these deals will happen.

\section{Set a Medium-Term Goal}

If the estimates of human resource demand and supply has been made then the next step is to determine the medium-term objectives and is accompanied by the development of an action plan that will be used to achieve these goals. This step is carried out with the cooperation 
between HR planners with other relevant managers within the organization. Different types of objectives in the short and medium term to reflect the differences in the types of changes that may occur in the forecast period of 2-3 years. Thus the short-term objective of which attract, assess and assign human resources in the job. While the long-term goals such readjustment HR skills, attitudes, and behaviors that fits against a major change in business requirements such as adjustments HR practices to match the changing needs of HR.

\section{Medium-term Programs}

Medium-term program that is often used in general is training (training and retraining). Training programs for example in the form of basic skills for a new human resources to become familiar with their workplace or job, employee training time to improve his skills, for example, internships and partnerships with educational institutions. There are several factors or underlying reasons for organizations to develop these programs include:

(1) Changes in technology.

Training or training is expected SDM can improve his skills can thus keep up with technology.

(2) The shift from manufacturing-based into a service-based.

The manufacturing company is different from the company's services, therefore the necessary training in order to have sufficient capacity in human resources these adjustments.

(3) Lack of manpower

Amid the uncertain change required manpower shortage in quantity and quality is often the case that Companies feel the need to prepare candidates for HR early on, for example, when they still were instituted education.

(4) The economic conditions are forcing their downsizing. The demands of downsizing must be accompanied by an increase in the quality or the competence of existing human resources to be more productive and high performing organizations so that performance remains intact even increased.

(5) The need for organizations to adapt diverse workforce. It is very necessary for the demands of organizational complexity that demands human diversity.

\section{Evaluate the Medium-Term Program}

Psychologists spend a little more time to evaluate the medium-term human resource programs include a higher level of uncertainty. Also because the scope of the broader program, the unit of analysis for the proper evaluation is often a level of productivity of the entire department or business unit. Although the industrial psychologists have determined methods of measuring individual performance level assessment, measurement techniques can not be translated easily into the measurement of productivity.

More recently, the experts started to apply their measurement expertise to develop suitable measurement. The progress of the task will be significantly valuable for medium-term planning and long-term planning.

\section{5.. Long-Term Human Resource Planning}

Long-term HR planning is very important for the organization in line with market changes and the development of an increasingly competitive world that led to the shift of human 
resources as sources for excellence komptetif and survival of the organization. It is the activity of demand integration expertise and knowledge of HR planners and all other executive responsibilities for strategic planning. Although there are many types of long-term planning effort, which is discussed in this article is a succesion planning (Jackson and Schuler, 1990).

\section{Estimating demand and Long-Term Deals}

The main concern of long-term business (succesion planning) in the organization is what type of manager is required to pursue business in the twenty-first century, and how do we create a confidence that we have it? Program succesion planning is a very complex system designed to secure long-term health of the organization. Succesion planning is planning made by the company to fill the executive positions of the most important (Dessler, 2000). Key activities in succesion planning is to identify high-potential human resources, identifying the competencies required and provide learning experiences to develop these competencies.

The developed program includes various components, namely the selection procedure, the development plan, coaching, performance review regularly and systematically, and career planning that involves employees to plan and monitor their own progress. The organization is a dynamic system that is inherent in a dynamic environment. When plans are needed for the future, THAT future needs will be different from your current needs. Popular wisdom has long been known that type of leader who

Different is effective for different business conditions. Pembeuatan early stages of growth in succesion planning is very difficult. For future needs inconsistent with the needs of today, the challenge is to find ways to maximize the effectiveness of managers within the organization that is now growing rapidly while at the same time providing managers experience helps them to develop the skills they need in the stage of maturity the organization's environmental future.

Another type of major changes that the organization may be experienced during a planning horizon of several years is a modification of the competition strategy. Such a change from the rapid growth to maturity stability, changes in competitive strategy may have significant implications for the type of manager is required. Succesion planning is beneficial for the organization:

1). Ensuring the sustainability of leadership that is prepared to occupy strategic positions.

2). Involve senior management team in the process of reviewing the talents of leadership in the organization.

3). Placing human diversity issues within the organization.

4). Guiding the development activities of key executives.

5). Check back structures, processes, and systems of the business unit or organization.

6). Adjustments to other HR functions in support of the new leadership.

7). Thus providing a contribution to shareholder value.

\section{Programming and Implementation of Long-Term}

For many organizations succesion planning and career development is a tool to integrate diversity in the organizations of the subgroup. Organizations use succesion planning to move 
the talented human resources through differences to build a consistent organizational culture and organizational units (McManis \& Leibman, 1988). The challenges of integrating diversity is something great program and requires expertise in implementation. Although talks on a long-term human resource planning program this focused on succesion planning, it should be noted here that other types of long-term HR planning is also important. However, this article offers only one example to illustrate what can be portraits when used long-term HR planning to expand relations kompstisi strategy and HR practices.

\section{Of Succession Planning for Management Succession}

Business environment changes more quickly and competitively will greatly affect the organization in determining HR policies. Hence it is often the organization needs transformation in the business environment, the organization felt the need to rethink how to modify the succession planning into management succession. With succession management organizations create a more dynamic approach and flexibility in preparing future executives and have the leadership in accordance with the business challenges facing the organization.

\section{Evaluation of Long-Term Programs}

Now we have a lot of knowledge about how to develop and improve the long-term HR poragram been raised through systematic research. A lot of knowledge about the behavior of individuals and the development has been obtained by the analysis of the massive amount of data that is raised with a large scale, in line with management planning system. Questions such as how the ability and personality factors contribute to a successful managerial career, and they were also informed about the changing patterns of life and between generations (Jackson \& Schuler, 1990). Evaluation of long-term planning emphasis on the ability to predict individual outcomes, such as career advancement and satisfaction. Evaluation of long-term programs can also use organizational outcomes such as share price, market share and others. Integrating the needs of business and human resource planning as an indicator is as legitimate criteria for a successful evaluation.

\section{Linkage HR Planning and Strategic Business Planning}

Gerstein and Reisman (1983), Harvey (1983), Leontiades (1982), Magliore (1982), Sweet (1982), describes the human resource strategy as to develop a match between a particular strategy with organizational conditions and specific aspects of certain of the expertise of HR, One approach involves matching skills and interests karakteristi general manager of environmental products / markets. Alternative approaches to create a match is a policy and process HR organizations with specific strategic choice (Smith, 1982). HR policies should be adjusted to to describe the future strategic business needs, rather than reflecting current conditions or execution ago (Smith, 1982). Overall compatibility issues deserve reassessment. Some research indicates that achieving a match is not always desirable. Furthermore, focusing on maximizing compatibility can be counter-productive if the organizational changes necessary or if the organization telang lifted competitive purpose contrary to equalize the competitive environment in which complex (Lengnick-Hall \& McDaniel, 1984).

Selection and determination of the appropriate strategic business determined by the quality of human resources in planning and implementing strategies established business. Integrating HR functions into planning santa strategic business is important for HR as a function of the 
company's management is an important function in the success of the implementation of the plan strategic organization. The integration of HR functions in the management of various unitswork in your organization to the process of managing organizational resources can be done effectively and efficiently.

Integration of human resources planning in the strategic business planning can be seen from the paradigm of the relationship of the two that is, of administrative linkage, linkage one way, two way linkage and integrative linkage that shows how much the role of the HR function into the organization's business strategy.

\section{Administrative Linkage}

In this connection, the Human Resource Department (HRD) plays a role tradidional. In conditions such as this relationship with the top manager Other department managers less importance to the HRD, and considers HR is not an asset in business decisions.

\section{One Way Linkage}

Types of relationships such as this is usually a sequential relationship between strategic planning and HR functions. Although theoretically this relationship to flow to the other (from strategic planning to human resource planning). HR functions mendesai system and programs to support the company's strategy. Therefore, HR react to a strategic initiative but it can not influence it, although top managers convinced that HR strategic importance for business success but they have not looked at that HR as a strategic business partner.

\section{Two Way Linkage}

In this connection it is characterized as a reciprocal relationship and interdependence between strategic planning with human resource functions. Top managers and business planners acknowledge that business planning affects and is affected by the activities of the HR function. HR functions deemed trustworthy and is considered an important and proactive in responding to personal human resources and help determine the strategic decisions of the company. Therefore, the consequences of this relationship between the line manager, business planner and HR staff related each other as a strategic partner.

\section{Integrative Linkage}

In this connection, characterized by the presence of dynamic, interactive relationship between the strategic planning of the HR function. Formal and informal interaction will always happen. HR senior executives will be viewed as a strategic business partner that together with other senior eksekutih, including in making strategic decisions when their attention could not be seen directly in the SDM. Integrate HR planning into the organization's strategic business planning have implications on strategic business performance improvement organization that in turn competitive advantages will be realized. Some aspects related to the integration of HR in business strategy, among others:

Cost advantage, keep costs low in the use SDM, down sizing through analysis of headcount reduction and elimination of work instead of human resources; (2) The delegation, increase kapaitas for action through streamlining processes, increasing the involvement of human resources, new measurements under delegation, and the risk of compensation; (3) Organizational, span of control, Centralized, decentralized, internal growth, acquisitions, and divestitures; (4) Competitiveness, to obtain customer satisfaction, product quality, 
productivity, and other components of the effort to improve the quality of security, and innovation; (4) Effectiveness oraganisasional, reaching flexibility, efficiency, integration and diferensasi, effectiveness and interdependence within the team, clarity and relationships between the role of human resources; (5) Expertise of employees, in order to develop HR competencies can be through training in leadership development; (6) Managing the diversity of human resources, to increase the capabilities and motivation of human resources through the preparation of personnel, barriers, Kariri development, performance management, communication, and employee involvement, and focusing the issue of work life; (7) Global Competitiveness, applying global business perspective, managing multinational Kariri, and determine the important points of the global integration of the global organization.

\section{HR Planning and Compatitive Advantage}

Understanding the factors that determine profit for organizations has been the observation of academics and business practitioners last few years. Source based on the idea organizations provide the economic foundation for discussing the role of $\mathrm{HR}$ in the organization competitive advantage (Barney, 1991). This view focuses on the organization's resources are derived from human capital such as skill, competence, ability, and intelligence.

Characteristics of HR organizations including knowledge, experience, skills, commitment to the organization of human resources, can provide sources of competitive advantage for organizations (Barney, 1991). Therefore human resource planning should be done as well as possible so that the existing human resources within the organization with all its potential to support competitive advantage of organizations. By integrating HR planning into business strategy capable of increasing the expected HR competitive advantage through competency development, self actualization, able to cooperate role in a teamwork, supplying a major contribution in the improvement of overall organizational performance.

Increased competitive advantage of organizations will contribute positively to the existence of the organization. Through the integration of HR functions in the organization's business strategy is expected to achieve a sustainable competitive advantage and provide value-added organization, improve business performance and increase the organization's strategic flexibility, thus it will be able to adapt to changing business environment and the competitive dynamic.

\section{Conclusion}

At the implementation level HR planning both short-term planning, medium term and long term must be adapted to the conditions and needs of the organization and the changing business environment faced. The longer the term of HR planning has a high level of risk as uncertainty (uncertainty) and can not be controlled (uncontroll). Therefore let no linkages between human resource planning, strategic business planning and strategic environmental changes. Long-term HR planning plays an important role in line with the changing role of HR as a source of competitive advantage.

The development of a dynamic business environment requires a long-term human resource planning is a succession planning (succession planning) has developed into a new generation of the management succession (succession management). Succesion management organization is expected to give birth to a top manager and strategic leadership to anticipate 
changes in strategic and business challenges.

In administrative linkage between HR planning and business planning separately. In this connection, the HR function is not important in business planning. Because the purpose of HR planning is to ensure that the right person is the right place and the right time, it must be linkage with the total planning of the organization. In the one-way linkage relationship between HR planning and business planning is weak. Business planning, where they exist, have defined their needs thereby manufacture an example reactive HR planning.

Many organizations now recognize that they benefit from two-way linkage between business and human resource planning. With two-way linkage, business plan considered that they are influenced by human considerations such as cost and availability of human resources. More recently the organization began to move into integrative linkage. In organizations that use this linkage integrative organizational effectiveness facilitated by HR executives to participate fully as members of the top team manpagement.

Effectiveness between HR planning and business planning in realizing competitive advantage will be determined by the extent of the linkage of the two. HR planning becomes more complex as the time horizon for planning to reach further into the future, so it is not surprising that organizations are becoming involved in activities HR planning long term only after becoming proficient in planning short-term and long-term (Mills, 1985).

HR planning should be consistent and integrated with environmental factors, organizational capability, organizational characteristics, strategic business organizations that in turn competitive advantage (competitive advantage) will be achieved. Through HR planning, companies can integrate HR functions into an organization's business strategy to improve individual performance and ultimately accumulate in organizational performance.

Finally, the final challenge of HR planning is to balance the needs of the organization and human resources present and the future. Criteria balance measured whether HR is now located in the right place, doing the right thing and adapt appropriately to the different activities and new when organizational change is needed because of the challenges of a dynamic business environment changes. If these problems can be anticipated in order to achieve competitive advantage.

\section{References}

Baird, L., \& Meshoulam, I. (1988). Managing Two Fits of Strategic Human Resource Management. Academy of Management Review, 13, 116-128. https://doi.org/10.5465/AMR.1988.4306802

Barney, J. (1991), Firm Resources and Sustained Competitive Advantage. Journal of Management, 17, 99-120. https://doi.org/10.1177/014920639101700108

Buller, P. F. (1988). succesfull partnership: HR and strategic planning at eight top firms. Organizational Dynamics, 17, 27-43. https://doi.org/10.1016/0090-2616(88)90017-4

Cascio, W. F. (1986). Human Resource Costing: The Financial Impact of Behavior in Organizations. Boston: Kent.

DeSanto, I. F. (1983). Work Force Planning and Corporate Strategy. Personnel Administrator, 28(10), 33-42. 
Dessler, G. (2000). Human Resource Management (6th Edition), New Jersey Prentice Hall, Inc.

Fombrun. (1982). Environmental Trends Create New Presures on Human Resource. Journal of Business Strategy, 3(1), 61-69. https://doi.org/10.1108/eb038957

Gerstein, M., \& Reisman, H., (1983). Strategic Selection: Matching Executive to Business Condition. Sloan Management Review, 24(2), 1-18

Harvey, L. J. (1983). Effective Planning for Human Resource Development. Personnel Administrator, 28(10), 45-52.

Jackson, S. E., \& Schuler, R. S. (1990). Human resources planning: Challenges for industrial / organizational psychologist. American Psychologist, 45, 223-239. https://doi.org/10.1037/0003-066X.45.2.223

Lengnick-Hall, C. A., \& McDaniel, R. R. (1984). Scanning Policies, Structure, and adaptability in Humana Service Sysstem. American Business Review, 2(1), 12-23.

Leontiades, M. (1982). ti manager Choosing The Right Fit The Strategy. Journal of Business Strategy, 2(2), 58-69. https://doi.org/10.1108/eb038967

Leidman, M., Bruer, R., \& Maki, B. (1996). Succession management: The next generation of succession planning. Human Resource Planning, 19(3), 16-29.

Migliore, R. H. (1982). Linking Strategy, Performance, and Pay. Journal of Business Strategy, 3(1), 90-94. https://doi.org/10.1108/eb038961

Mills, D. Q. (1985: July-August). Planning With People in Mind. Harvard Business Review, 97-105.

Olian, J. D., \& Rynes, S. L. (1984). Organizational Staffing: Integrating Practice With Strategy. Industrial Relations, 23, 170-183. https://doi.org/10.1111/j.1468-232x.1984.tb00895.x

Pfeffer, J. (1995). Producing sustainable competitive advantage through the effective management of people. Of the Academy of Management Executive, 19(1), 55-72. https://doi.org/10.5465/ame.1995.9503133495

Robbins, S. P. (2000). Organizational Behavior: Concepts, Controversies, Applications, Englewood Cliffs. New Jersey: Prentice Hall, Inc. https://doi.org/10.1002/1099-1379(200009)21:6\%3C649::AID-JOB45\%3E3.0.CO;2-\#

Rowland, K. M., \& Summers, S. L., (1981). Human Resource Planning: A Second Look. Personnel Administrator, 26(12), 73-80

Rothwell, S. (1995). Human resource planning. In J. Storey (Ed). Human Resource Management: A Critical Text (pp. 167-202). London: Routledge.

Schuler, R. S., \& Walker, J. W. (1990). Human resources strategy: Focusing on issues and actions. Organization $\quad$ Dynamics, Summer: https://doi.org/10.1016/0090-2616(90)90045-Q

Schuller, R. S., \& Jackson, S. E. (1987). Linking competitive strategies with human resource management practices. Academy of Management Executive, 1(3), 207-219. https://doi.org/10.5465/AME.1987.4275740

Smith, E. C., (1982). Strategic Business Planning and Human Resources: Part I. Personnel 


\section{Macrothink}

Journal of Social Science Studies

ISSN 2329-9150 2017, Vol. 4, No. 2

Journal, 61(8), 606-610

Sweet, J., (1982), How Can Support Your manpower Development Strategic Plan. Journal of Business Strategy, 3(1), 77-81

Vickerstaff, S. (1989). Human Resource Planning. In C. Molander (Ed.), Human Resource Management. Bromley: Chartwell-Bratt

Zedeck, S., \& Mosier, K. L. (1990). The Family and Work in Employing Organization. American Psychologist, 45, 240-251. https://doi.org/10.1037/0003-066X.45.2.240

\section{Copyright Disclaimer}

Copyright for this article is retained by the author(s), with first publication rights granted to the journal.

This is an open-access article distributed under the terms and conditions of the Creative Commons Attribution license (http://creativecommons.org/licenses/by/3.0/). 